\title{
Theoretical Efficiency of a Thermionic Diode
}

\author{
HAGAI SHAKED \\ Nuclear Research Center-Negev, Israel \\ (Z. Natursforschg. 20 a, 1588-1591 [1965] ; received 11 August 1965)
}

\begin{abstract}
A theoretical analysis of the efficiency of a thermionic diode is made in the highly efficient region of very low anode potential $\left(V_{\mathrm{a}}<1\right.$ volt $)$. Maximum efficiency is calculated as a function of the cathode temperature for optimum values of anode potential. The calculations are performed for different values of usuable power density, anode temperature and emissivity of electrodes.
\end{abstract}

The analysis is based on the potential energy diagram of an electron shown in Fig. $1^{*}$. Energy in the form of heat is supplied to the electron at the Fermi level of the cathode. If the electron gains enough speed to overcome the potential energy bar-

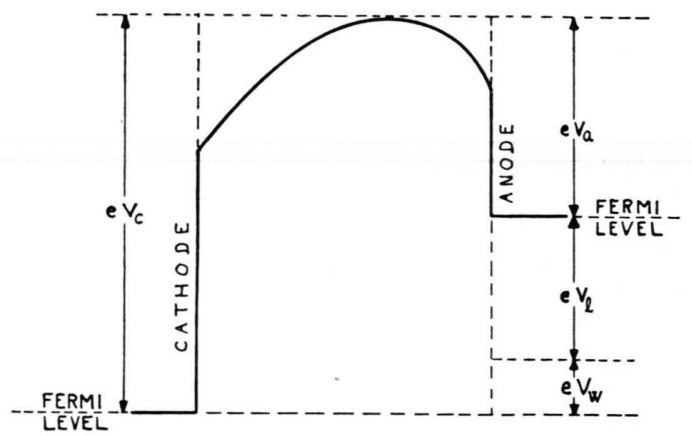

Fig. 1. Potential energy diagram of an electron in a therm ionic diode.

rier $\left(e V_{\mathrm{c}}\right)$, it will reach the anode. It will lose at least $e V_{\text {a }}$ units of energy to the anode lattice (this energy will have to be removed by cooling the

\footnotetext{
* Glossary:

$A=$ Coefficient in the Richardson eq. (1) $\left(120 \mathrm{amp} / \mathrm{cm}^{2} /{ }^{\circ} \mathrm{K}^{2}\right)$.

$B=$ Function defined in eq. (6) (watt $\left./ \mathrm{cm}^{2}\right)$.

$e=$ Charge of the electron $\left(1.602 \times 10^{-19}\right.$ coul. $)$.

$F=$ Function of $T_{\mathrm{c}}$ defined in eq. (4) (volts).

$H=$ Conductive heat loss at the cathode lead wire per unit area of the cathode (watt $\left./ \mathrm{cm}^{2}\right)$.

$I=$ Current per unit area of the cathode $\left(\mathrm{Amp} / \mathrm{cm}^{2}\right)$.

$k=$ Boltzman constant $\left(1.3803 \times 10^{-23} \mathrm{Joule} /{ }^{\circ} \mathrm{K}\right)$.

$L=$ Lorenz number $\left(2.45 \times 10^{-8} \mathrm{watt} \cdot \Omega /{ }^{\circ} \mathrm{K}\right)^{6}$.

$P=$ Usable power density (power dissipated in the load per unit area of cathode) (watt $/ \mathrm{cm}^{2}$ ).

$Q=$ Power dissipated in the load and in the cathode lead wire per unit area of the cathode $\left(w a t t / \mathrm{cm}^{2}\right)$.

$T=$ Temperature $\left({ }^{\circ} \mathrm{K}\right)$.

$T_{0}=$ Room temperature $\left(300^{\circ} \mathrm{K}\right)$.

$V=$ Voltage (volt)
}

anode). The electron will next lose $e V_{1}$ units of energy while doing usable work at the load. Before returning to the FERMI level of the cathode it will loose $e V_{\mathrm{w}}$ units of energy at the cathode lead wire ${ }^{1}$. The performance of such a diode was discussed by several workers ${ }^{2-5}$. It was shown that the efficiency $(\eta)$ increases as the anode potential $\left(V_{\mathrm{a}}\right)$ decreases.

There is, however, an optimum value of $V_{\mathrm{a}}$, beyond which a further decrease of $V_{\mathrm{a}}$ will lead to a decrease in the efficiency (due to an increase in the back emission). This optimum value depends in general on the anode temperature $\left(T_{\mathrm{a}}\right)$, and varies in the range 0.5 to 1.0 volt for $T_{\mathrm{a}}<500{ }^{\circ} \mathrm{C}$. In $1962, V_{\mathrm{a}}$ values, smaller than 1.6 volts were considered to be impractical for the operation of thermionic diodes ${ }^{2}$. Two years later Chapman $^{6}$ and $\mathrm{KLUGE}^{4}$ reported on thin film coated electrode materials having minimum $V_{\mathrm{a}}$ values in cesium vapor of 1.4 and 1.0 volt, respectively. With this, experimentalists have arrived at the doorsteps of the optimum range which was mentioned above. The present analysis covers this optimum range of low anode potential and high efficiency.

\footnotetext{
$W=$ Joule heat developed at the cathode lead wire per unit of the cathode (watt $/ \mathrm{cm}^{2}$ ).

$\varepsilon=$ Emissivity.

$\eta=$ Efficiency.

$\sigma=$ STEFAN BoltzMan constant $\left(5.67 \times 10^{-12} \mathrm{watt} / \mathrm{cm}^{2} /{ }^{\circ} \mathrm{K}^{4}\right)$.

Subscripts: a Anode, c Cathode, 1 Load, w Cathode lead wire.

1 Unlike anode lead wire, whose cross sections may be large, cathode lead wires must have a relatively small cross section, in order to reduce heat loss through conduction.

2 N. S. Rasor, Advan. Energy Conv. 2, 545 [1962].

3 J. M. Houston and H. F. Webster, Advan. Electron. Electron Phys. 17, 125 [1962].

4 W. KLUGE, Z. Naturforschg. 19 a, 595 [1964].

5 J. M. Houston, J. Appl. Phys. 30, 481 [1959].

6 R. A. Chapman, J. Appl. Phys. 35, 2832 [1964].
} 

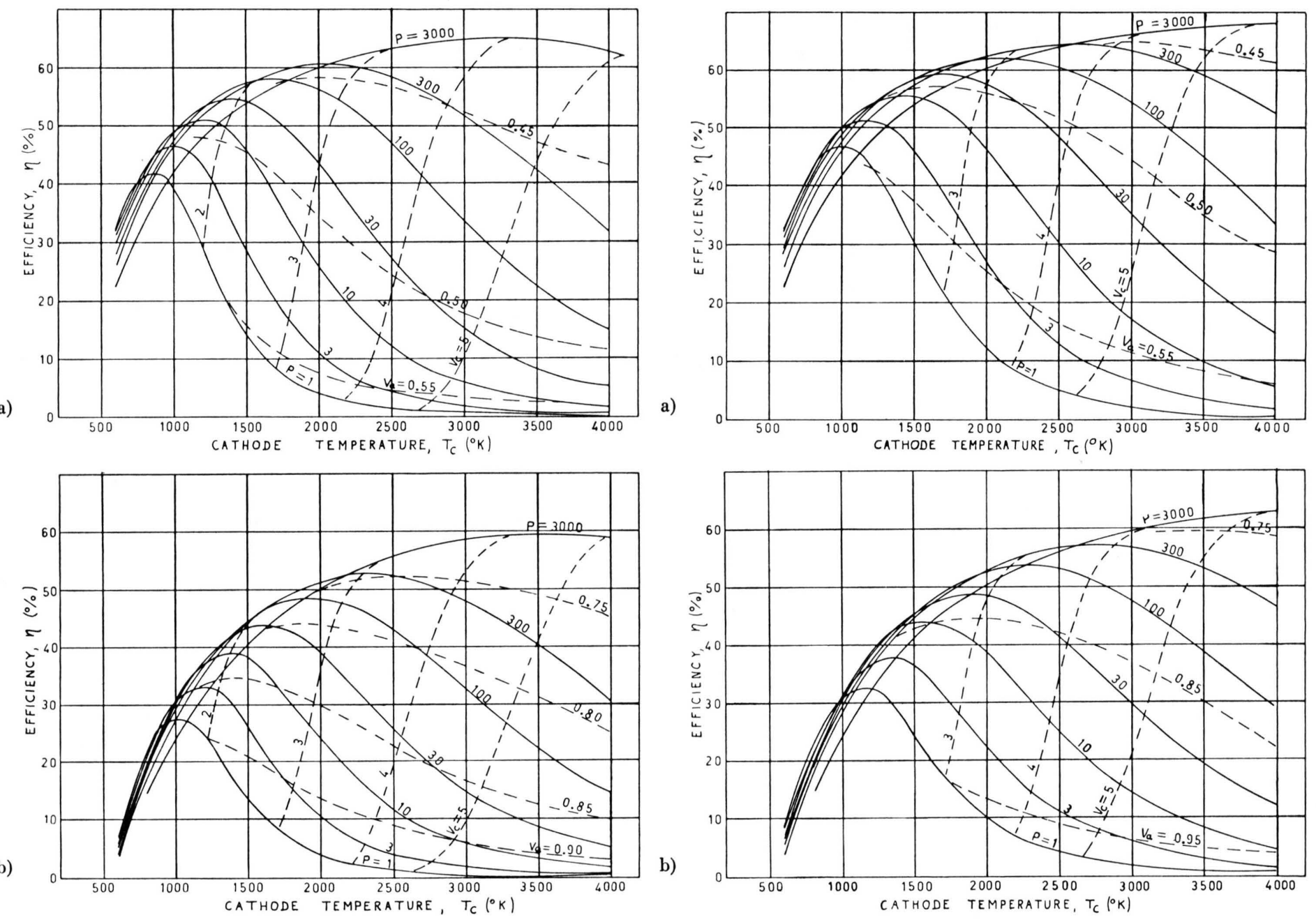

Fig. 2. Efficiency of thermionic diode, black $(\varepsilon=1)$ electrodes $\left(V_{\mathrm{a}}\right.$ and $V_{\mathrm{c}}$ in volt, $P$ in watt $\left./ \mathrm{cm}^{2}\right)$. (a) $T_{\mathrm{a}}=300{ }^{\circ} \mathrm{K}$, (b) $T_{\mathrm{a}}=500{ }^{\circ} \mathrm{K}$.

Fig. 3. Efficiency of thermionic diode, tungsten electrodes $\left(V_{\mathrm{a}}\right.$ and $V_{\mathrm{c}}$ in volt, $P$ in watt $/ \mathrm{cm}^{2}$ ). (a) $T_{\mathrm{a}}=300^{\circ} \mathrm{K}$, (b) $T_{\mathrm{a}}=500{ }^{\circ} \mathrm{K}$. 


\section{Analysis}

The Richardson equation ${ }^{2}$ was used for the cathode and anode current.

$$
I_{\mathrm{i}}=A T_{\mathrm{i}}^{2} \exp \left[-\frac{e V_{\mathrm{i}}}{k T_{\mathrm{i}}}\right], \quad \mathrm{i}=\mathrm{a}, \mathrm{c} .
$$

The net current is equal to

$$
I=I_{\mathrm{c}}-I_{\mathrm{a}} .
$$

The efficiency of a thermionic diode, having a potential energy diagram, as shown in Fig. 1, is given by

$\eta=\frac{I\left(V_{\mathrm{c}}-V_{\mathrm{a}}\right)-W}{\varepsilon \sigma\left(T_{\mathrm{c}}{ }^{4}-T_{\mathrm{a}}{ }^{4}\right)+H+I_{\mathrm{c}}\left(V_{\mathrm{c}}+2 k T_{\mathrm{c}} / e\right)-I_{\mathrm{a}}\left(V_{\mathrm{c}}+2 k T_{\mathrm{a}} / e\right)}$.

The terms $2 k T_{\mathrm{i}} / e, \mathrm{i}=\mathrm{a}, \mathrm{c}$, represent the heat, carried by the electrons in the form of kinetic energy (sometimes referred to as the electron cooling terms). In case that $I_{\mathrm{a}}=0\left(i \cdot e \cdot I=I_{\mathrm{c}}\right)$ it has been shown ${ }^{5,3}$ that the efficiency was maximized by the following relations:

$$
\left.\begin{array}{l}
W=[\eta /(2-\eta)]^{1 / 2} F\left(T_{\mathrm{c}}\right) I, \\
H=\frac{1-\eta}{\eta} W, \quad F\left(T_{\mathrm{c}}\right)=\left(T_{\mathrm{c}}{ }^{2}-T_{0}{ }^{2}\right)^{1 / 2} L^{1 / 2},
\end{array}\right\}
$$

It is assumed that these relations will approximately maximize $\eta$ even when $I_{\mathrm{a}} \neq 0$. Then eq. (3) and (4), after some algebra, reduce to

where

$$
\eta=(2 P-Q) /(P+B)
$$

$Q=I\left(V_{\mathrm{c}}-V_{\mathrm{a}}\right)$,

$$
\begin{aligned}
B= & \varepsilon \sigma\left(T_{\mathrm{c}}{ }^{4}-T_{\mathrm{a}}{ }^{4}\right)+I_{\mathrm{c}}\left(V_{\mathrm{a}}+2 k T_{\mathrm{c}} / e\right) \\
& -I_{\mathrm{a}}\left(V_{\mathrm{a}}+2 k T_{\mathrm{a}} / e\right) .
\end{aligned}
$$

$P$ is equal to the usuable power density, that is, power dissipated at the load, namely

$$
P=Q-[\eta /(2-\eta)]^{1 / 2} I F\left(T_{\mathrm{c}}\right) \text {. }
$$

The pair of eqs. (5) and (7) is mathematically equivalent to

$$
\eta=\mathfrak{h}_{1}\left(P, V_{\mathrm{a}}, T_{\mathrm{c}}, T_{\mathrm{a}}\right) .
$$

Although the explicit form of $\mathfrak{h}_{1}$ is unknown, $\eta$ can be calculated for any value of the independent variables by using eq. (5) and (7). The indepen-

7 Royal McBee Corporation, Westchester Ave., Port Chester, N. Y.

${ }^{8}$ D. E. Gray (Coordinating Ed.), Am. Inst. Phys. Handbook, McGraw-Hill Book Co., Inc., New York 1963. dent variable $V_{\mathrm{a}}$ was made dependent by requiring that it will maximize $\eta$, namely

$$
\partial \eta / \partial V_{\mathrm{a}}=0 \text {. }
$$

Thereby the problem was reduced, so that $\eta$ can be evaluated from

$$
\eta=(2 P-Q) /(P+B)
$$

with the constraints

$$
\begin{gathered}
P-Q+[\eta /(2-\eta)]^{1 / 2} I F\left(T_{\mathrm{c}}\right)=0, \\
\eta \frac{\partial B}{\partial V_{\mathrm{a}}}+\frac{\partial Q}{\partial V_{\mathrm{a}}}=0
\end{gathered}
$$

which is the mathematical equivalent of

$$
\eta=\mathfrak{h}_{2}\left(P, T_{\mathrm{c}}, T_{\mathrm{a}}\right) \text {. }
$$

$\eta$ was calculated from eq. (10) with the aid of a computer code for the LGP-30 digital computer ${ }^{7}$. Final results for two cases are presented (Figs. 2,3). In one case (Fig. 2) cathode and anode are assumed to be black $(\varepsilon=1)$ and in the other (Fig. 3) the cathode and anode materials are assumed to have the emissivity of tungsten ${ }^{8}$. The multiple reflection emissivity in the latter case was calculated from $\varepsilon=\left[1 / \varepsilon\left(T_{\mathrm{c}}\right)+1 / \varepsilon(T)-1\right]^{-1}, \quad T=\left[T_{\mathrm{c}} T_{\mathrm{a}}\right]^{1 / 2}$.

Geometric mean temperature, rather than anode temperature is used, because of the non-grayness of the metallic surface ${ }^{9}$.

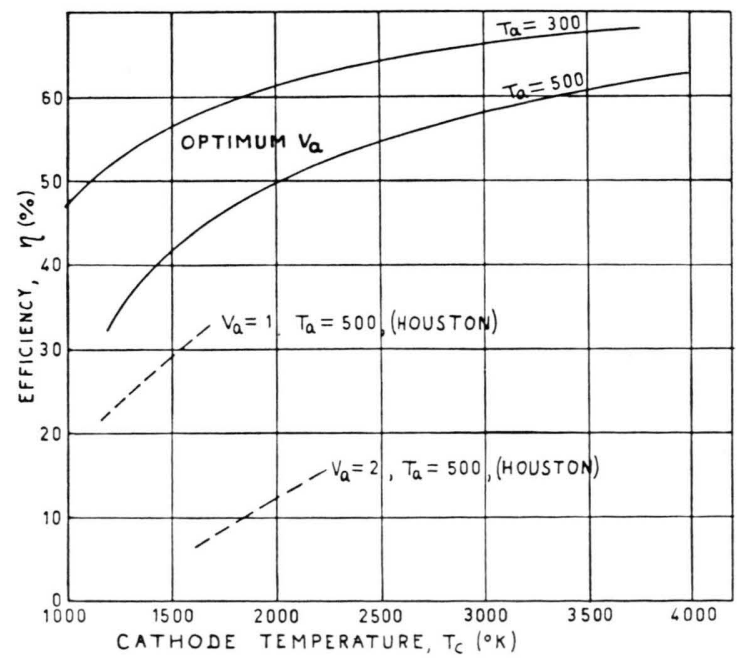

Fig. 4. Efficiency in the optimum $V_{\mathrm{a}}$ range $\left(T_{\mathrm{a}}\right.$ in ${ }^{\circ} \mathrm{K}, V_{\mathrm{a}}$ in volt).

9 H. Giedt, Heat Transfer, Van Nostrand Co. Inc., 1957. Page 248. 


\section{Conclusions}

The locus of the points of maximum efficiency (Fig. 3) is shown in Fig. 4 (solid lines). For comparison, curves of maximum efficiency for tungsten electrodes, as computed by Houston ${ }^{5}$, are also given (broken line) in Fig. 4. It is evident from Fig. 4 that if a diode could be made to work with an opti- mum anode potential of $0.8-0.9$ volts (Fig. 3 ), the efficiency of present day diodes $\left(V_{\mathrm{a}}>1.6\right.$ volts $)$ could perhaps be more than tripled.

\section{Acknowledgements}

The author is indebted to Dr. N. S. RAsor of the Thermo Electron Eng. Corp. for his constructive criticism, and to Mr. Y. BoneH of the Nuclear Research Center - Negev for his help with the computations.

\title{
Non-linearities and Discontinuities of the Photoemission from Multi-Alkali Cathodes at Nitrogen Temperatures*
}

\author{
H. Hora ** R. Kantlehner, and N. Riehl \\ Physics Department of the Technische Hochschule, Munich \\ (Z. Naturforschg. 20 a, 1591-1599 [1965] ; received 28 September 1965)
}

\begin{abstract}
An account is given of measurements relating to the temperature dependence of the photoemission of multialkali cathodes at temperatures in the region of $80^{\circ} \mathrm{K}$. These measurements show intensity-dependent and spectrally dependent non-linearities with hysteresis in which pronounced discontinuities of the quantum yield of the photoemission occur up to a factor of 2 . With a temperature constancy in the region of $\pm 0.01{ }^{\circ} \mathrm{K}$ these discontinuities are fully reproducible. Because of the extremely high temperature sensitivity of the effect interesting prospects are afforded when it is used for detecting thermal radiation on the basis of photoelectrons that can be utilized particularly well technically.
\end{abstract}

In discussing the increase of the photoemission from alkali halides and other polar crystals just below the fundamental-band absorption, whereby the photoelectrons are excited secondarily by excitons apparently produced by the light ${ }^{1}$, F. SeIrz suggested that "such a process would depend on incident radiation intensity or would lead to hysteresis and irreversible changes".

APKER and $\mathrm{T}_{\mathrm{AFT}}{ }^{1}$, on the other hand, established complete invariability of their results and thus strict linearity of the photoemission when the light intensity is varied by more than a factor of 10 . In the many works that have appeared since then no doubts have been cast on their findings ${ }^{2}$.

In the following an account is given of measurements of the photoemission from multi-alkali cathodes. These measurements show the dependence on the light intensity predicted by SEITz (non-linearity, hysteretic properties and discontinuities) and are reproducible only by reactivation in keeping with the hysteresis. At the same time extremely high sen-

* Work supported by the Fraunhofergesellschaft (Contract No. T 532 I 203).

* Institut für Plasmaphysik, Garching bei München.

1 L. Apker and E. TAFt, Phys. Rev. 81, 698 [1951]. sitivity of the properties of the cathode on temperature is obtained. The latter was taken as the starting point of these investigations when a complete anomaly in the temperature dependence of the photoemission was found for the first time in $1960^{3}$ at multi-alkali cathode temperatures in the region of $110^{\circ} \mathrm{K}$. It was established that the quantum yield increased in a reproducible manner by a factor of 3 for photon energies of $2 \mathrm{eV}$ when the temperature drops by $1{ }^{\circ} \mathrm{K}$. This factor was determined from measurements in which, it may be pointed out by way of completion, not the photoemission with constant monochromatic light at various cathode temperatures was measured, but the spectral distribution at progressively changing temperatures.

The application of this temperature effect in a radiation detector has been proposed. Here the photoelectric current of the cathode, which is suitably illuminated in the range in question, is modified very finely when the radiation to be measured heats the cathode ${ }^{4}$. When continued appropriately

2 E. Taft, H. Philipp, and L. Apker, Phys. Rev. 113, 156 [1959].

3 G. Frischmuth-Hoffmann, P. Görlich, and H. Hora, Z. Naturforschg. 15 a, 1014 [1960].

${ }^{4}$ H. Hora, DBPat. 1137876. 